\title{
Paradoxical sleep deprivation increases plasma endothelin levels
}

B.D. Palma ${ }^{1}$

A. Gabriel Jr. ${ }^{2}$,

M. Bignotto ${ }^{1}$

and S. Tufik ${ }^{1}$

\author{
1Departamento de Psicobiologia and \\ 2Laboratório de Investigação M édica (LIM), \\ Disciplina de Clínica Médica, Escola Paulista de M edicina, \\ Universidade Federal de São Paulo, São Paulo, SP, Brasil
}

\section{Correspondence \\ B.D. Palma \\ Departamento de Psicobiologia \\ EPM, UNIFESP \\ Rua Napoleão de Barros, 925 \\ 04024-002 São Paulo, SP \\ Brasil \\ Fax: +55-11-5572-5092 \\ E-mail: bia@ psicobio.epm.br}

Presented at the XVI Annual Meeting of the Federação de Sociedades de Biologia Experimental, Caxambu, MG, Brazil, August 29 - September 1, 2001.

Research supported by AFIP. Publication supported by FAPESP.

.......................

Received April 12, 2001 Accepted October 4, 2001

\section{Abstract}

The endothelins (ET-1, 2 and 3) constitute a family of 21 amino acid peptides with potent biological activities. ET-1 is one of the most potent endogenous vasoconstrictors so far identified and its increased concentration in plasma appears to be closely related to the pathogenesis of arterial hypertension as well as to obstructive sleep apnea (OSA). OSA patients exhibit repetitive episodes of apnea and hypopnea that result in hypoxia and consecutive arousals. These patients are chronically sleep deprived, which may aggravate the hypertensive features, since literature data show that sleep deprivation results in hypertension both in humans and in animals. Based on the reported relationship between ET-1, hypertension and sleep deprivation consequences, the purpose of the present study was to determine plasma ET concentrations in paradoxical sleep-deprived animals. Male Wistar rats, 3 to 4 months old ( $\mathrm{N}=10$ per group), were deprived of sleep for 24 and $96 \mathrm{~h}$ by the platform technique and plasma ET-1/2 was measured by radioimmunoassay. Analysis of plasma revealed that 96 $h$ of sleep deprivation induced a significant increase in ET-1/2 release $(6.58 \mathrm{fmol} / \mathrm{ml})$ compared to control $(5.07 \mathrm{fmol} / \mathrm{ml})$. These data show that sleep deprivation altered plasma ET- $1 / 2$ concentrations, suggesting that such an increase may participate in the genesis of arterial hypertension and cardiorespiratory changes observed after sleep deprivation.

Endothelins (ET-1, 2 and 3) constitute a family of 21 amino acid peptides with potent biological activities. The three isomers present slightly different $\mathrm{N}$-terminal amino acid sequences, yet similar biological activities. ET-1 is the only family member produced by endothelial cells (1), and is also produced by many types of cells, including neurons and astrocytes in the central nervous system, hepatocytes, and Sertoli cells, among others. ET2 and ET-3 are mainly produced within the kidney and intestine (2). ET-1 is released
Key words

- Endothelin

- Sleep deprivation

- Rat

- Hypertension under the influence of chemical or physical stimuli such as hypoxia (3). ET-1 production is regulated in vitro and in vivo by a variety of hormones, other vasoactive substances, and conditions of vascular stress (2). ET-1 is a powerful mitogenic substance, being the most potent endogenous vasoconstrictor identified thus far, and seems to be intimately involved in the pathogenesis of heart failure, kidney disease and hypertension (for a review, see 4).

One of the most common sleep disorders 
is obstructive sleep apnea (OSA), which is characterized by repetitive episodes of upper airway collapse during sleep, resulting in airflow interruption despite persisting respiratory efforts. Several epidemiological and animal studies have identified OSA as an important risk factor for systemic hypertension, but a direct etiologic link between the two disorders has yet to be definitively established $(5,6)$. Some studies have provided suggestive evidence that, besides involvement of the neural circulatory control mechanisms, other factors, such as the induction of ET-1 release by episodes of OSA, may contribute to the risk for the patients (7). OSA patients exhibit repetitive nocturnal apneas and hypopneas that result in hypoxia and consecutive arousals. These patients are chronically sleep deprived, because of frequent awakenings at the termination of apneic episodes.

Sleep deprivation may aggravate hypertensive features, inasmuch as it is known to result in hypertension in both humans and animals $(8,9)$. Sleep deprivation characteristically occurs in a number of sleep disorders in humans, including insomnia, OSA and fibromyalgia. This is the primary justification for the establishment of controlled experimental models of sleep deprivation. Paradoxical sleep deprivation studies using several species have produced mixed results, ranging from minor effects to severe changes and death (for a review, see 10). The cause of death is still unclear.

Assuming that there are cardiorespiratory changes observed during the period after paradoxical sleep deprivation (11) and that ET-1 participates in the genesis of hypertension and heart disease, the present study was designed to evaluate whether paradoxical sleep deprivation impairs ET-1 secretion in sleep-deprived animals.

Male Wistar rats weighing $\sim 300 \mathrm{~g}$ were subjected to sleep deprivation using the modified multiple platform technique (12). The animals were placed inside a filled water tank $(127 \times 44 \times 44 \mathrm{~cm})$ containing 15 narrow platforms $(6.5 \mathrm{~cm}$ in diameter), submerged in water until $1 \mathrm{~cm}$ below the surface. In this procedure, the animal is aroused from sleep when the characteristic loss of muscle tone that accompanies paradoxical sleep causes it to fall off the platform.

One day before the beginning of the study, the animals were adapted to the water tank for a period of $1 \mathrm{~h}$. The animals were divided into three groups ( $\mathrm{N}=10$ /group). One group was deprived of sleep for $24 \mathrm{~h}$ (24-h sleep deprivation) and the other, for $96 \mathrm{~h}$ (96-h sleep deprivation). Control animals $(\mathrm{N}=10)$ were maintained in their home cage in the same room where deprivation took place. All groups had free access to food and water throughout the study.

Immediately after the end of the sleep deprivation, the animals were ether-anesthetized and submitted to blood sampling by cardiac puncture. Blood was collected into vials containing sodium citrate and centrifuged at $2300 \mathrm{rpm}$ for $10 \mathrm{~min}$. Plasma was extracted, stored in plastic tubes and frozen at $-70^{\circ} \mathrm{C}$ until determination of ET-1/2 levels. ET was determined using an ET-1/2 $\mathrm{I}^{125}$ radioimmunoassay kit (Amersham International plc, Little Chalfont, Buckinghamshire, UK). The lower limit of detection for ET- $1 / 2$ was $0.5 \mathrm{fmol} / \mathrm{ml}$ and the inter- and intra-assay coefficients of variation were 10.4 and $4.1 \%$, respectively. Cross-reactivities of the assay with ET-1, ET-2, ET-3 and big ET were 100, 204, 0.0024 and $37.9 \%$ (human; 1-38), respectively.

ET-1/2 data were analyzed by one-way ANOVA, followed by the Duncan multiple range test, with the level of significance set at $\mathrm{P} \leq 0.05$.

ANOVA revealed a difference among groups $\left[\mathrm{F}_{(2,27)}=3.31 ; \mathrm{P} \leq 0.05\right]$. Post hoc comparison showed that the 96 -h sleep deprivation group exhibited a higher response than the control $(\mathrm{P}<0.03)$ and 24-h sleep deprivation $(\mathrm{P}<0.04)$ groups. ET-1/2 levels are shown in Figure 1. The present results show that 96 
$\mathrm{h}$ of sleep deprivation by the modified multiple platform technique resulted in an increase of plasma ET-1/2 levels. Twenty-four hours of paradoxical sleep deprivation did not alter the plasma ET-1/2 levels. These time points were chosen based on a pilot study in which we observed activation of endothelial cells only after 24 and $96 \mathrm{~h}$ of paradoxical sleep deprivation.

Numerous studies suggest that increased ET production or release may contribute to the pathogenesis of hypertension (4). The possible involvement of ET in the development or maintenance of arterial hypertension is based on the assumption that these peptides possess potent vasoconstricting and long-lasting pressor effects and may play an important role as circulating and/or local hormones, affecting vascular tonus and/or local blood flow.

According to our data, ET-1/2 may contribute to the hypertension observed after paradoxical sleep deprivation $(8,9)$. The exact mechanism is unknown, but there are some likely explanations for the alteration in the pattern of blood pressure after sleep deprivation. First, Mion Jr. and Krieger (8) have reported that paradoxical sleep deprivation may impair baroreceptor control function. It seems unlikely that a peripheral dysfunction could explain this impairment. Since angiotensin II, acting on the central nervous system, produces impairment in baroreflex control (13), and overactivity of the renin-angiotensin system could partly account for the alteration in baroreceptor function. It was observed that rapid eye movement sleep deprivation of longer duration is associated with increased hyperresponsiveness to centrally administered angiotensin II (14). Second, other studies suggest that lack of sleep may increase circulating norepinephrine, which mediates peripheral vasoconstriction via $\alpha$ adrenergic receptors, leading to increased blood pressure and heart rate $(9,15)$. ET-1 potentiates the vasoconstriction caused by norepinephrine (16) and catecholamines, in turn, potentiate the action of ET. Synergistic effects of ET-1 with norepinephrine and with the renin-angiotensin system raise the possibility of the existence of a common pathway in the hypertension-producing mechanism after sleep deprivation. However, Kato et al. (17) have noted that a shorter period of sleep deprivation in humans results in increased blood pressure and no change in heart rate. These effects are not mediated by sympathetic drive. These authors assume that production of ET may be enhanced.

As reviewed by Battistini et al. (4), ET-1 production or release in endothelial and other cells is regulated by several vasoactive substances, a variety of hormones, growth factors and cytokines, among other factors. According to Kanse et al. (18), glucocorticoids have been shown to regulate ET secretion. Recently, Suchecki and Tufik (12) showed that both ACTH and corticosterone levels are increased by the multiple platform technique used to induce paradoxical sleep deprivation. Several lines of evidence support the notion that sleep deprivation is a stressful method. Moreover, it is still unclear whether sleep deprivation by itself is a stressful stimulus. Thus, it is tempting to speculate that elevation of ET levels observed after paradoxical sleep deprivation may be mediated by activation of the hypothalamus-pituitary-adrenal axis.

Recently, Kähler et al. (19) demonstrated that oxidative stress increases the activity of the ET-1 promoter, preproendothelin-1 mRNA and big ET-1 protein synthesis. Interestingly, exposure of animals to the single platform technique results in increased oxi-

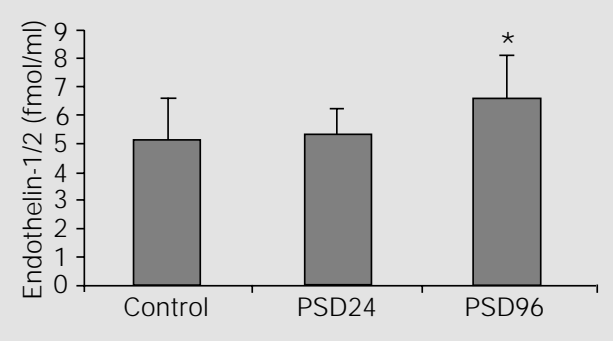

Figure 1. Plasma levels of endothelin-1/2 (fmol/ml) after paradoxical sleep deprivation. Values are reported as mean $\pm \mathrm{SEM}$. Control $(\mathrm{N}=10)$; PSD24 - paradoxical sleep deprivation for 24 h $(\mathrm{N}=10) ;$ PSD96 - paradoxical sleep deprivation for $96 \mathrm{~h}$ ( $\mathrm{N}=$ 10). *P $\leq 0.05$ compared to control and PSD24 groups (ANOVA). 
dative stress, reflected by reduced levels of the antioxidant glutathione in hypothalamus and thalamus (20). According to these data, a paradoxical sleep deprivation-induced oxidative process may contribute to the augmented plasma ET-1 levels.

Such findings indicate that paradoxical sleep deprivation disrupts vital biological processes necessary for physical health; however, how brain and body functions become compromised is not yet fully understood. The most important factor is that paradoxical sleep loss (to different extents) is experienced by almost everybody and, thus, probably can be considered a near natural phenomenon in terms of applicability of the knowledge for the ultimate goal, human welfare. Sleep loss can induce a variety of serious problems, which have been neglected as subjects of study.

Our results showed that paradoxical sleep deprivation increased plasma ET-1/2 levels, suggesting that such an increase may participate in the genesis of arterial hypertension observed after paradoxical sleep deprivation. Vasoconstrictor and mitogenic effects of ET-1 may contribute to the development of chronic conditions such as hypertension and cardiovascular disease in situations of sleep deprivation. This result adds further evidence demonstrating sleep deprivationinduced physiological alterations. Future studies should provide a clearer understanding of the mechanisms involved in the paradoxical sleep deprivation-induced increase of ET secretion.

\section{Acknowledgments}

The authors wish to thank Donizeti Babinska for excellent technical assistance.

\section{References}

1. Yanagisawa $M$, Kurihara $H$, Kimura $S$, Tomobe Y, Kobayashi M, Mitsui Y, Yazaki Y, Goto K \& Masaki T (1988). A novel potent vasoconstrictor peptide produced by vascular endothelial cells. Nature, 332 : 411-415.

2. Rubanyi GM \& Polokoff MA (1994). Endothelins: molecular biology, biochemistry, pharmacology, physiology, and pathophysiology. Pharmacological Reviews, 46: 325-415.

3. Simonson MS (1993). Endothelins: multifunctional renal peptides. Physiological Reviews, 73: 375-411.

4. Battistini $B, D^{\prime}$ Orleans-J uste $P \&$ Sirois $P$ (1993). Endothelins: circulating plasma levels and presence in other biologic fluids. Laboratory Investigation, 68: 600-628.

5. Brooks D, Horner RL, Kozar LF, RenderTeixeira CL \& Phillipson EA (1997). Obstructive sleep apnea as a cause of systemic hypertension. J ournal of Clinical Investigation, 99: 106-109.

6. Hla KM, Young TB, Bidwell T, Palta M, Skatrud J B \& Dempsey J (1994). Sleep apnea and hypertension. A populationbased study. Annals of Internal Medicine, 120: 382-388.

7. Phillips BG, Narkiewicz K, Pesek CA,
Haynes WG, Dyken ME \& Somers VK (1999). Effects of obstructive sleep apnea on endothelin- 1 and blood pressure. J ournal of Hypertension, 17: 61-66.

8. Mion J r D \& Krieger EM (1988). Blood pressure regulation after deprivation of rapid-eye-movement sleep in rats. J ournal of Hypertension, 6 (Suppl 4): S74-S76.

9. Lusardi P, Zoppi A, Preti P, Pesce RM, Piazza E \& Fogari R (1999). Effects of insufficient sleep on blood pressure in hypertensive patients: a 24-h study. American J ournal of Hypertension, 12 (Part 1): 63-68.

10. Rechtschaffen A, Bergmann BM, Everson CA, Kushida CA \& Gilliand MA (1989). Sleep deprivation in the rat: $X$. Integration and discussion of the findings. Sleep, 12 : 68-87.

11. De Mesquita S \& Hale GA (1992). Cardiopulmonary regulation after rapid-eye movement sleep deprivation. J ournal of Applied Physiology, 72: 970-976.

12. Suchecki D \& Tufik S (2000). Social stability attenuates the stress in the modified multiple platform method for paradoxical sleep deprivation in the rat. Physiology and Behavior, 68: 309-316.

13. Guo GB \& Abboud FM (1984). Angio- tensin II alternates baroreflex control of heart rate and sympathetic activity. American J ournal of Physiology, 246: H80-H89.

14. Marson $O$, Saragoça $M A$, Ribeiro $A B$, Bossolan D, Tufik S \& Ramos OL (1983). Anteroventral third ventricle and renin-angiotensin-system. Interaction in the twokidney, one clip hypertensive rats. Hypertension, 5 (Suppl V): V90-V93.

15. Bergmann BM, Everson CA, Kushida CA, Fang VS, Leitch CA, Schoeller DA, Refetoff S \& Rechtschaffen A (1989). Sleep deprivation in the rat: $V$. Energy use and mediation. Sleep, 12: 31-41.

16. Tabuchi $\mathrm{Y}$, Nakamaru $\mathrm{M}$, Rakugi $\mathrm{H}, \mathrm{Na}-$ gano M, Mikami H \& Ogihara T (1989). Endothelin inhibits presynaptic adrenergic neurotransmission in rat mesenteric artery. Biochemical and Biophysical Research Communications, 161: 803-808.

17. Kato $M$, Phillips BG, Sigurdsson $G$, Narkiewicz K, Pesek CA \& Somers VK (2000). Effects of sleep deprivation on neural circulatory control. Hypertension, 35: 1173-1175.

18. Kanse SM, Takahashi K, Warren J B, Ghatei M \& Bloom SR (1991). Glucocorticoids induce endothelin release from vascular smooth muscle cells but not endo- 
thelial cells. European J ournal of Pharmacology, 199: 99-101.

19. Kähler J, Mendel $S$, Weckmüller J, Orzechowski HD, Mittmann C, Koster R, Paul M, Meinertz T \& Munzel T (2000).
Oxidative stress increases synthesis of big endothelin-1 by activation of the endothelin-1 promoter. J ournal of Molecular and Cellular Cardiology, 32: 1429-1437.

20. D'Almeida V, Lobo LL, Hipólide DC,
Oliveira AC, Nóbrega J N \& Tufik S (1998). Sleep deprivation induces brain regionspecific decreases in glutathione levels. NeuroReport, 9: 2853-2856. 